\title{
Association between left atrial reverse remodeling and maintenance of sinus rhythm after catheter ablation of persistent atrial fibrillation
}

\author{
Yoshihiko Kagawa $^{1} \cdot$ Eitaro Fujii $^{1}$ (D) Satoshi Fujita ${ }^{1} \cdot$ Masaaki Ito $^{1}$
}

Received: 18 April 2019 / Accepted: 12 July 2019 / Published online: 25 July 2019

(c) The Author(s) 2019

\begin{abstract}
The success rate of catheter ablation of persistent atrial fibrillation (AF) is not satisfactory, for reasons that are unclear. The purpose of this study was to examine the relationship between left atrial reverse remodeling after ablation and recurrence of $\mathrm{AF}$ in patients with persistent AF. One hundred and thirty-two patients with persistent AF were enrolled. Extensive encircling pulmonary vein isolation plus ablation of complex fractionated atrial electrograms was performed. Bepridil or amiodarone was prescribed for 3 months after ablation. All patients were studied by serial echocardiography and 24-h ambulatory electrocardiogram at baseline, for the day after ablation, and at 1-, 3-, and 6-month intervals after ablation. Recurrence of AF was observed in 42 patients at 2-year follow-up. The duration of AF (median 12 (IQR 6-37) vs 8 (IQR 5-17) months, $p<0.05$ ), and early recurrence of $\mathrm{AF}(69 \mathrm{vs} 26 \%, p<0.05)$ after ablation were significantly different between the patients with $\mathrm{AF}$ recurrence and those without. The left atrial dimensions at 3 months ( $40 \pm 6$ vs $44 \pm 6 \mathrm{~mm}, p<0.001)$ and 6 months $(40 \pm 6$ vs $44 \pm 6 \mathrm{~mm}, p<0.001$ ) were significantly smaller than those just after ablation in the patients without AF recurrence. A $5 \%$ reduction from baseline in the left atrial dimension at 6 months after ablation was associated with freedom from late $\mathrm{AF}$ recurrence $(p<0.05)$. Left atrial reverse remodeling after ablation of persistent AF was associated with freedom from late recurrence of $\mathrm{AF}$.
\end{abstract}

Keywords Persistent atrial fibrillation $\cdot$ Ablation $\cdot$ Left atrial reverse remodeling $\cdot$ Prognostic factor

\section{Introduction}

Pulmonary vein isolation is an established and effective treatment for patients with paroxysmal atrial fibrillation (AF) [1]. However, the success rates of catheter ablation for patients with persistent AF are not satisfactory, for reasons that are unclear. Intensive ablation of the left atrium (LA) including complex fractionated atrial electrogram (CFAE) ablation combined with extensive pulmonary vein isolation (EPVI) improves outcomes of catheter ablation in patients with persistent AF [2], but a substantial portion of these patients experience relapse of AF. The STAR AF II trial clearly showed that additional substrate modification (CFAE or linear lesions) following EPVI offers no benefit in AF reduction [3]. A critical issue is how to identify patients in

Eitaro Fujii

fujii-e@clin.medic.mie-u.ac.jp

1 Department of Cardiology and Nephrology, Mie University Graduate School of Medicine, 2-174 Edobashi,

Tsu 514-8507, Mie, Japan whom sinus rhythm maintenance can be achieved after catheter ablation. In some cases, the size of LA decreases after catheter ablation, which is considered to indicate improvement of LA remodeling [4]. We assessed the hypothesis that atrial reverse remodeling after catheter ablation would be associated with maintenance of the sinus rhythm in patients with persistent $\mathrm{AF}$.

\section{Methods}

\section{Study population}

This case-control study included 132 consecutive patients with persistent AF. All patients underwent AF ablation between April 2012 and April 2016, and were followed up for 2 years. AF was classified as persistent if there was a failure to self-terminate within 7 days. Long-standing persistent AF was defined as AF lasting for more than 1 year. This study was approved by the Mie University Hospital 
Institutional Review Boards (reference number: 3038), and all patients gave their written or opt-out informed consent.

\section{Ablation procedure}

After informed written consent was obtained, an electrophysiological study was performed in the postabsorptive state under light sedation [5]. Trans-esophageal echocardiography was performed to exclude the possibility of LA thrombus just before ablation in all patients [6]. After internal jugular and femoral vein punctures, a heparin bolus (100 $\mathrm{U} / \mathrm{kg}$ ) was administered, and continuous infusion of heparin was provided thereafter to maintain an activated clotting time of between 250 and $350 \mathrm{~s}$. A diagnostic duodecapolar catheter was placed in the coronary sinus via the jugular vein. Three long sheaths were inserted through the femoral vein and introduced in the LA through a single transseptal puncture guided by intracardiac echocardiography. Two eicosapolar circumferential catheters (Lasso 2515, Biosense Webster, Diamond Bar, CA, USA and Optima 2015, St. Jude Medical, St. Paul, MN, USA) were introduced in the LA through the transseptal long sheaths, and an ablation catheter with a 3.5-mm irrigated tip (EZ Steer Thermocool, Biosense Webster, Diamond Bar, CA, USA) was introduced in the LA. All imaging was performed using a biplane flatpanel detector angiographic suite (Allura Xper FD10/10 angio system; Philips Healthcare, Best, Netherlands). Intraprocedural three-dimensional (3D) rotational angiography of LA (3D-ATG) was performed with $15 \mathrm{~mL}$ of contrast medium $+15 \mathrm{~mL}$ of saline injected by hand directly into the bilateral upper pulmonary veins via the Swartz long sheaths placed in the left and right superior pulmonary veins during rapid ventricular pacing at 200 beats per minute. 3D-ATG was performed from the right oblique at $59^{\circ}$ and to the left oblique at $100^{\circ}$ of $\mathrm{C}$-arm rotation at a sampling rate of 30 frames per second for a total of $3.8 \mathrm{~s}$ [7-9]. After the rotational angiography, the data were automatically transferred from the FD10/10 detector System to the EP Navigator Workstation. The 3D LA-PV images were reconstructed using the standard 3D reconstruction algorithms available on the EP Navigator Workstation within $1 \mathrm{~min}$, and were seamlessly integrated into the $\mathrm{CARTO}^{\circledR}$ system using the local area network in our hospital, within 2-3 min [9]. The 3D LA-PV image was then integrated with the live fluoroscopy. Extensive encircling pulmonary vein isolation [10] plus ablation of complex fractionated atrial electrograms (CFAE) $[2,11]$ was performed. Radiofrequency energy was delivered with a target temperature of $40{ }^{\circ} \mathrm{C}$, at a power setting of 25-30 W. Each target site was ablated for 20-30 s. The endpoints of ablation were complete elimination or dissociation of PV potentials determined using the circumferential catheter and no further CFAE observed at the targeted sites.

\section{Echocardiography}

Transthoracic echocardiography was performed at baseline, the day after ablation, and at 1-, 3-, and 6-month intervals after ablation. LA diameter was measured through antero-posterior diameter from the parasternal long-axis view. The LV ejection fraction (LVEF) was assessed by Simpson's method. The ratio of peak early $(E)$ to late $(A)$ diastolic transmitral flow velocity $(E / A)$ was calculated using pulsed Doppler echocardiography. Tissue Doppler imaging (TDI) of the mitral annular motion was obtained from the apical 4-chamber view. The sample volume was placed at the septal and lateral mitral annuli, and early $\left(e^{\prime}\right)$ and late $\left(a^{\prime}\right)$ diastolic annular velocities were measured. The ratio of $\mathrm{E} / \mathrm{e}^{\prime}$ was calculated. The rate of LA reduction at 6 months after ablation was defined as (LA diameter (post 1 day)-LA diameter (post 6 months))/LA diameter (post 1 day) $\times 100(\%)$.

\section{Follow-up}

All patients were monitored in the hospital for at least 2 days after their procedures. Bepridil or amiodarone was prescribed after ablation for 3 months and was then stopped if AF recurrence was not observed. At 1, 3, 6, 12, and 24 months after ablation, patients underwent clinical review and 24-h ambulatory ECG monitoring to identify asymptomatic arrhythmias. Early AF recurrence (ERAF) was defined as any recurrence of $\mathrm{AF}>30 \mathrm{~s}$ during the first 3 months of follow-up. Late recurrence was defined as any recurrence of AF $>30$ s between 3 and 24 months. Oral anticoagulation was discontinued 6 months after ablation in patients with a CHADS 2 score of $\leq 1$.

\section{Statistical analysis}

Continuous variables are expressed as the mean \pm standard deviation (SD) or median and interquartile range, and categorical variables as absolute values and percentages. Results were analyzed using the SPSS 22.0 software (SPSS Inc., Chicago, IL, USA). Continuous data were evaluated using the unpaired Student $t$ test or nonparametric Mann-Whitney test when dealing with non-normal distributions. Categorical data were analyzed using the Chi squared test or Fisher's exact test. Kaplan-Meier analysis with the log-rank test was used to determine the probability of freedom from recurrent AF. Multivariate Cox regression analysis was performed to determine the independent predictors of recurrence of AF. A receiveroperating characteristic analysis was performed to define 
cutoff values, and the cutoff values were defined by minimizing the expression of $(1 \text {-sensitivity })^{2}+(1 \text {-specificity })^{2}$. Significance was established at $P<0.05$.

\section{Results}

\section{Patient characteristics}

Patient characteristics are summarized in Table 1. The mean age of the patients was $63 \pm 10$ years, 107 patients $(81 \%)$ were male, 70 patients $(53 \%)$ had hypertension, and 21 patients $(16 \%)$ had a history of congestive heart failure. The duration of AF was 9 months, and there were 54 patients (41\%) with long-lasting AF. The mean $\mathrm{CHADS}_{2}$ and $\mathrm{CHA}_{2} \mathrm{DS}_{2}$-VASc scores were $1 \pm 1$ and $2 \pm 2$ points, respectively.

\section{Catheter ablation and clinical outcomes}

EPVI was performed in all patients, confirmed by entrance and exit block. Ablation of CFAE was performed in the patients who had persistent AF after PV isolation $(n=125$,

Table 1 Patient baseline characteristics

\begin{tabular}{ll}
\hline Study population $(n=132)$ & Value \\
\hline Age, years & $63 \pm 10$ \\
Male, $n(\%)$ & $107(81)$ \\
Body mass index, $\mathrm{kg} / \mathrm{m}^{2}$ & $23.8 \pm 3.7$ \\
Duration of AF, months & $9(6-24)$ \\
Long-lasting AF, $n(\%)$ & $54(41)$ \\
Hypertension, $n(\%)$ & $70(53)$ \\
Heart failure, $n(\%)$ & $21(16)$ \\
Diabetes mellitus, $n(\%)$ & $19(14)$ \\
Stroke/TIA, $n(\%)$ & $17(13)$ \\
CHADS ${ }_{2}$ score & $1 \pm 1$ \\
CHA ${ }_{2}$ DS ${ }_{2}$-VASc score & $2 \pm 2$ \\
BNP, pg/ml & $112.9(65.1-175.0)$ \\
eGFR, mL/min/1.73 m ${ }^{2}$ & $66.7 \pm 19.8$ \\
ACE-I, $n(\%)$ & $15(11)$ \\
ARB, $n(\%)$ & $44(33)$ \\
Beta-blockers, $n(\%)$ & $56(42)$ \\
Calcium blockers, $n(\%)$ & $48(36)$ \\
Aldosterone blockers, $n(\%)$ & $6(5)$ \\
Alpha-blockers, $n(\%)$ & $1(1)$ \\
Diuretics, $n(\%)$ & $17(13)$ \\
AAD user, $n(\%)$ & $31(24)$ \\
\hline
\end{tabular}

Values are presented as mean $\pm \mathrm{SD}$, median (IQR), or $n(\%)$

$A A D s$ antiarrhythmic drugs, $A C E-I$ angiotensin-converting enzyme inhibitor, $A F$ atrial fibrillation, $A R B$ angiotensin receptor blocker, $B N P$ B-type natriuretic peptide, $e G F R$ estimated glomerular filtration rate, TIA transient ischemic attack
95\%). An additional linear ablation extending from the mitral valve annulus to the junction of the left inferior $\mathrm{PV}$ was performed in four cases, and cavotricuspid isthmus ablation was performed on the patients complicated with common atrial flutter $(n=10,8 \%)$. Superior vena cava isolation was performed in a few patients with $\mathrm{AF}$ recurrence $(n=4,3 \%)$. Cardiac tamponade occurred in one patient $(0.9 \%)$ during PV isolation, necessitating pericardial drainage, and three patients had vasospastic angina just after the ablation procedure [12].

During the follow-up period of 24 months, 125 patients (95\%) maintained sinus rhythm (SR) and 7 patients (5\%) were found to have persistent AF. ERAF occurred in 52 patients $(39 \%)$ within the 3 -month blanking period. Twenty-four patients (18\%) underwent re-ablation for $\mathrm{AF}$ recurrence. Of the 132 patients, 90 patients $(68 \%)$ were free from late recurrence of $\mathrm{AF}$ and 35 patients $(27 \%)$ had paroxysmal AF recurrence (Fig. 1).

\section{Comparison of clinical characteristics between the patients free from AF and those with recurrence}

Age, sex, BNP before ablation, a history of hypertension, diabetes mellitus, and strokes were not different between the patients with and without late recurrence of $\mathrm{AF}$ (Table 2). Duration of AF (12 (6-37) vs 8 (5-17) months, $p<0.05$ ), early recurrence of AF (69 vs $26 \%, p<0.05$ ), and continuation of antiarrhythmic drugs (57 vs $22 \%$, $p<0.05)$ were significantly different between the patients with and without AF recurrence (Table 2).

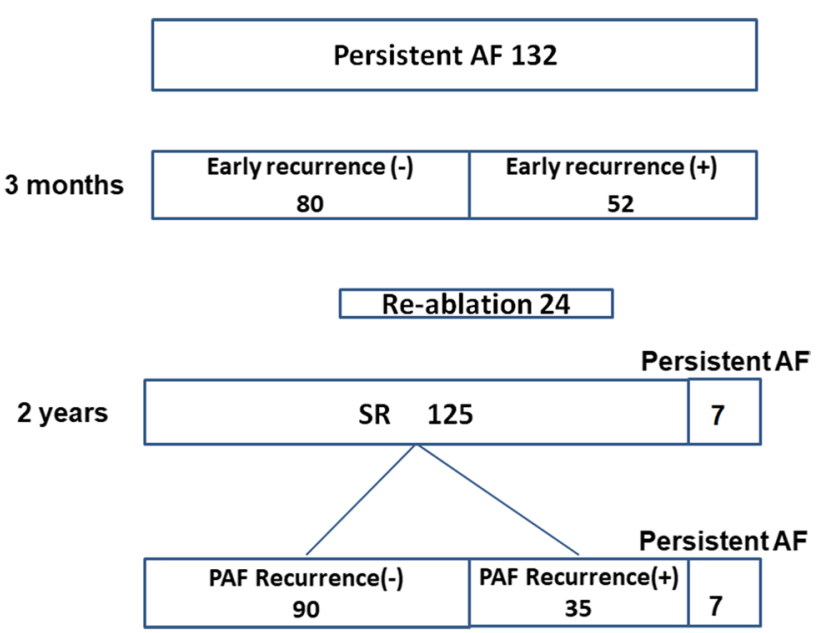

Fig. 1 Total results are shown in the flow diagram. $A F$ atrial fibrillation, $P A F$ paroxysmal AF, $S R$ sinus rhythm 
Table 2 Comparison of clinical characteristics between the patients with and without late recurrence of $\mathrm{AF}$

\begin{tabular}{llll}
\hline & Freedom from AF $(n=90)$ & Recurrence of AF $(n=42)$ & $P$ value \\
\hline Age, year & $62 \pm 10$ & $63 \pm 11$ & 0.805 \\
Male, $n(\%)$ & $72(80)$ & $35(83)$ & 0.495 \\
Body mass index, $\mathrm{kg} / \mathrm{m}^{2}$ & $24.0 \pm 3.8$ & $23.3 \pm 3.6$ & 0.449 \\
Duration of AF, months & $8(5-17)$ & $12(6-37)$ & 0.021 \\
Long-lasting AF, $n(\%)$ & $32(36)$ & $22(52)$ & 0.073 \\
Hypertension, $n(\%)$ & $49(54)$ & $21(50)$ & 0.438 \\
Heart failure, $n(\%)$ & $14(16)$ & $7(17)$ & 0.947 \\
Diabetes mellitus, $n(\%)$ & $9(10)$ & $10(24)$ & 0.099 \\
Stroke/TIA, $n(\%)$ & $12(13)$ & $5(12)$ & 0.773 \\
CHADS 2 score & $1 \pm 1$ & $1 \pm 1$ & 0.927 \\
CHA ${ }_{2}$ DS ${ }_{2}$-VASc score & $2 \pm 2$ & $2 \pm 2$ & 0.773 \\
BNP before ablation, pg/ml & $108.7(64.8-181.5)$ & $124.9(66.2-173.2)$ & 0.723 \\
eGFR, ml/min/1.73 m ${ }^{2}$ & $65.0 \pm 12.1$ & $69.9 \pm 29.7$ & 0.139 \\
ACE-I, $n(\%)$ & $8(9)$ & $7(17)$ & 0.251 \\
ARB, $n(\%)$ & $29(32)$ & $15(36)$ & 0.784 \\
Beta-blockers, $n(\%)$ & $34(38)$ & $22(52)$ & 0.134 \\
Calcium blockers, $n(\%)$ & $35(39)$ & $13(31)$ & 0.124 \\
Aldosterone blockers, $n(\%)$ & $1(1)$ & $4(7)$ & 0.200 \\
Alpha-blockers, $n(\%)$ & $1(1)$ & $0(0)$ & 0.609 \\
Diuretics, $n(\%)$ & $11(12)$ & $6(14)$ & 0.884 \\
Continuation of AADs, $n(\%)$ & $20(22)$ & $24(57)$ & 0.018 \\
Early recurrence of AF, $n(\%)$ & $23(26)$ & $29(69)$ & 0.015 \\
\hline
\end{tabular}

Values are presented as mean $\pm \mathrm{SD}$, median (IQR), or $n(\%)$

$A A D s$ antiarrhythmic drugs, $A C E-I$ angiotensin-converting enzyme inhibitor, $A F$ atrial fibrillation, $A R B$ angiotensin receptor blocker, $B N P$ B-type natriuretic peptide, $e G F R$ estimated glomerular filtration rate, $E R A F$ early recurrence of atrial fibrillation, TIA transient ischemic attack
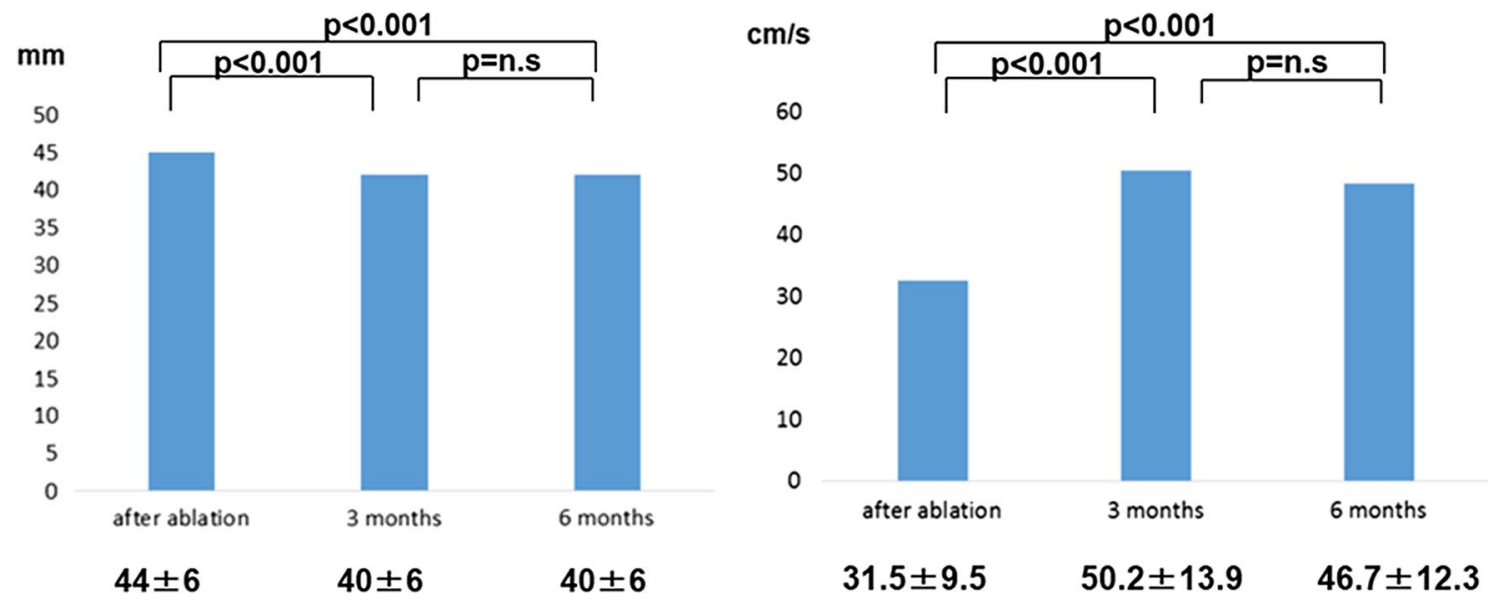

Fig. 2 Left panel: LA dimensions at 3 and 6 months decreased after AF ablation in the patients without AF recurrence. Right panel: transmitral A wave values at 3 and 6 months increased after ablation in the patients without AF recurrence. $A F$ atrial fibrillation, $L A$ left atrium

\section{Changes in echocardiographic parameters and BNP}

The left atrial dimensions at 3 months $(44 \pm 6$ vs $40 \pm 6 \mathrm{~mm}, p<0.001)$ and 6 months $(44 \pm 6$ vs $40 \pm 6 \mathrm{~mm}$, $p<0.001)$ were significantly smaller compared with just after ablation in the patients without AF recurrence (Fig. 2). The left atrial dimension at 3 months was significantly different between the patients with AF recurrence and without $[42 \pm 4$ vs $40 \pm 6 \mathrm{~mm}(p<0.05)]$ (Table 3$)$. The A wave amplitudes at 3 and 6 months were greater 
Table 3 Echocardiographic parameters

\begin{tabular}{llll}
\hline & $\begin{array}{l}\text { Freedom from AF } \\
(n=90)\end{array}$ & Recurrence of AF $(n=42)$ & $P$ value \\
\hline LAD at ablation, mm & $44 \pm 6$ & $45 \pm 6$ & 0.629 \\
LAD at 3 months, mm & $40 \pm 6$ & $42 \pm 4$ & 0.044 \\
LAD at 6 months, mm & $40 \pm 6$ & $42 \pm 5$ & 0.165 \\
A wave at ablation, cm/s & $32.8 \pm 10.7$ & $32.0 \pm 10.6$ & 0.730 \\
A wave at 3 months, cm/s & $50.5 \pm 14.8$ & $50.3 \pm 16.5$ & 0.723 \\
A wave at 6 months, cm/s & $48.8 \pm 15.8$ & $47.2 \pm 20.3$ & 0.614 \\
LVEF before ablation, \% & $61 \pm 11$ & $63 \pm 11$ & 0.550 \\
LVEF at ablation, \% & $64 \pm 9$ & $62 \pm 11$ & 0.332 \\
LVEF at 3 months, \% & $66 \pm 6$ & $66 \pm 9$ & 0.996 \\
LVEF at 6 months, \% & $65 \pm 7$ & $68 \pm 9$ & 0.331 \\
E/e' at ablation & $9.8 \pm 3.5$ & $9.9 \pm 4.7$ & 0.858 \\
E/e' at 3 months & $7.9 \pm 3.9$ & $8.2 \pm 5.8$ & 0.974 \\
E/e' at 6 months & $7.7 \pm 3.4$ & $8.4 \pm 4.8$ & 0.560 \\
Reduction of LAD at 3 months, \% & $8.5(4.4-13.2)$ & $5.7(-1.2-12.5)$ & 0.093 \\
Reduction of LAD at 6 months, \% & $7.4(3.8-13.4)$ & $4.3(0.0-10.2)$ & 0.022 \\
\hline
\end{tabular}

$L A D$ left atrial dimension, $L V E F$ left ventricular ejection fraction

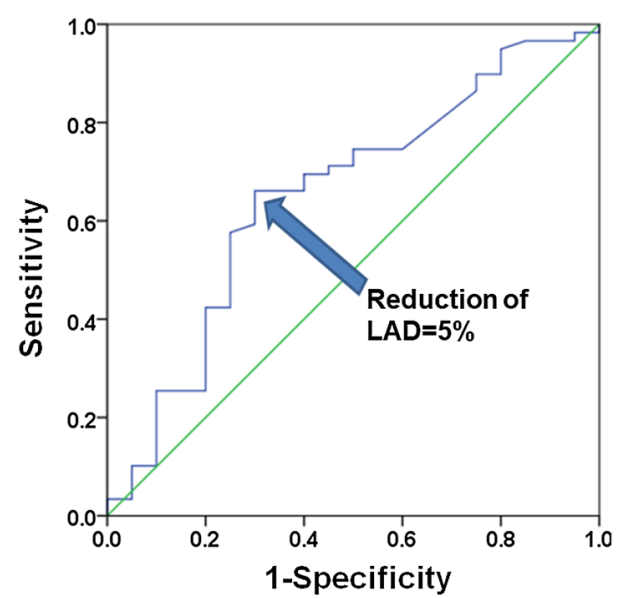

Fig. 3 Calculation of an optimal cutoff value using receiver-operating characteristic curve analysis with respect to the reduction rate of the left atrial dimension. The cutoff value of reduction of the left atrial dimension was $5 \%$. The area under the receiver-operating characteristic curve is 0.653 (95\% CI $0.51-0.80, p<0.05)$. $L A D$ left atrial dimension

than just after ablation in the patients without AF recurrence (Fig. 2). There were no differences in the values of LVEF at baseline, at 3, and at 6 months between the patients with and without AF recurrence. There was a significant decrease between the median BNP concentrations at baseline and those at 3 and 6 months ( 111.0 vs $34.9 \mathrm{pg} /$ $\mathrm{ml}, p<0.001 ; 111.0 \mathrm{vs} 30.4 \mathrm{pg} / \mathrm{ml}, p<0.001)$. The rate of LA reduction at 6 months had a significant relationship with late recurrence $(p<0.05)$. The cutoff value of the reduction of left atrial dimension was $5 \%$ (area under the curve $=0.653, p<0.05)($ Fig. 3).
Table 4 Results of Cox regression analysis for freedom from AF recurrence

\begin{tabular}{lllll}
\hline Covariates & $\beta$ & Standard error & $P$ value & Hazard ratio \\
\hline Age & -0.010 & 0.028 & 0.725 & 0.990 \\
Male & -0.531 & 0.670 & 0.404 & 0.588 \\
Duration of AF & 0.010 & 0.008 & 0.240 & 1.010 \\
$\geq 5 \%$ reduction of & -1.228 & 0.560 & 0.028 & 0.293 \\
$\quad$ LAD & & & & \\
ERAF & 0.642 & 0.525 & 0.221 & 1.900 \\
Continuation of & 0.775 & 0.517 & 0.134 & 2.170 \\
$\quad$ AADs & & & & \\
\hline
\end{tabular}

$A A D s$ antiarrhythmic drugs, $A F$ atrial fibrillation, $E R A F$ early recurrence of atrial fibrillation, $L A D$ left atrial dimension

\section{Outcome}

Cox regression analysis revealed that a reduction of LA dimension $\geq 5 \%$ at 6 months was associated with freedom from late recurrence of AF (Table 4). At month 24 of the follow-up period excluding blanking periods, $80 \%$ of the patients with a LA dimension reduction $\geq 5 \%$ at 6 months were free from AF, compared with $42 \%$ of the patients without (Log-rank test, $\mathrm{p}<0.01)$ (Fig. 4).

\section{Discussion}

This study demonstrated that a reduction of more than 5\% in LA dimension at 6 months after ablation was associated with freedom from late recurrence after catheter ablation of persistent AF. 


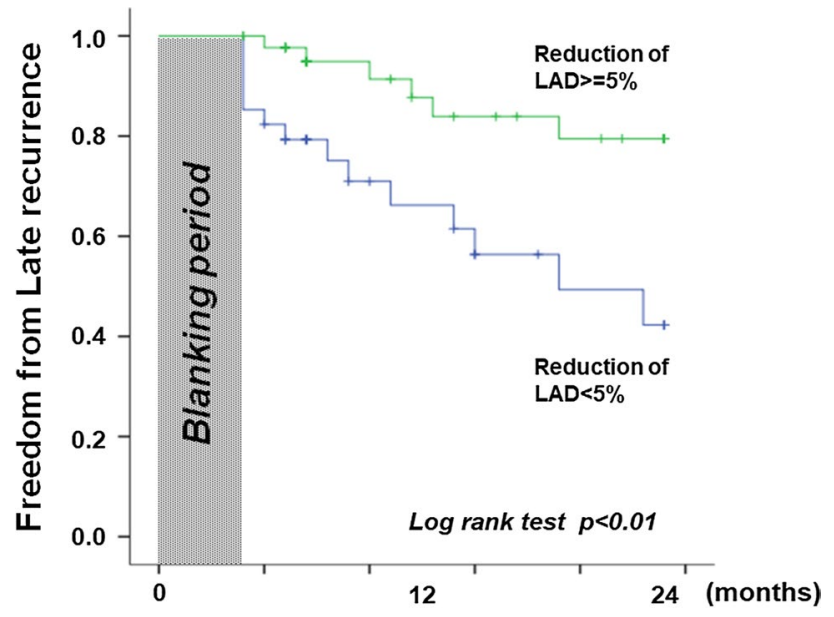

Fig. 4 Kaplan-Meier analysis of long-term freedom from atrial fibrillation $(\mathrm{AF})$ in patients with and without $5 \%$ reduction of left atrial dimension at 6 months after $\mathrm{AF}$ ablation. $L A D$ left atrial dimension

It was previously reported that the prognostic factors of AF ablation include ERAF, AF duration, LA size and hypertension [13-16]. The durations of AF and ERAF significantly affected the outcomes after AF ablation in our study, as in previous reports.

Reverse morphological remodeling of the LA by ablation for isolated AF was observed in several studies [4, 13, 14]. Tops et al. reported that the LA antero-posterior diameter showed a significant reduction in their SR group at 3 months of follow-up [13]. Beukema et al. reported that the LA dimension in persistent AF subjects who remained in sinus rhythm decreased from $44.0 \pm 5.8$ to $40.0 \pm 4.5 \mathrm{~mm}$ at 6 months after ablation, while in patients with recurrence of AF the LA dimension increased from $45 \pm 6.5$ to $49 \pm 5.4 \mathrm{~mm}$ [14]. A reduced or eliminated AF burden could lead to a reduction of LA volume after catheter ablation $[17,18]$. In our study, a reduction in LA volume at 6 months after ablation was seen in the patients who remained in sinus rhythm for the 2-year follow-up period.

$\mathrm{Wu}$ et al. reported that catheter ablation of AF improves structural remodeling of the PV ostia and LA. In that study, patients with persistent $\mathrm{AF}$ had a greater reduction in LA volume than those who had paroxysmal AF $\left(11.8 \pm 12.8 \mathrm{~cm}^{3}\right.$ vs $\left.4.0 \pm 11.2 \mathrm{~cm}^{3} ; P=0.04\right)$. Reverse remodeling of the PV ostial geometry may parallel the reduction of LA volume [18]. From an electrocardiographic point of view, Fujimoto et al. reported that $\mathrm{P}$ wave dispersion was useful for assessment of reverse remodeling after catheter ablation of AF [19].

We believe that the change in LA diameter may be used as a marker of AF recurrence, indicating continued use of antiarrhythmic drugs or the need for re-ablation. Based on our results, a smaller degree of reversibility can be expected in subjects with longer AF duration, due to progressive remodeling.

\section{Clinical implications}

The identification of a strong predictor of AF recurrence (i.e., reduction of LA diameter) makes it possible to distinguish patients with different long-term success probabilities. This stratification may help to identify patients who would benefit from antiarrhythmic drugs or a repeat procedure to prevent recurrent $\mathrm{AF}$.

\section{Limitations}

This was a single-center study, and any conclusions must be regarded with appropriate circumspection. LA volume measured by $\mathrm{CT}$ or MRI in AF ablation was reported previously [20,21]; although these modalities are more precise, we could easily speculate on the recurrence of AF based on whether LA remodeling after ablation was detected by twodimensional echocardiography. The left atrial volume index (LAVI) has been measured since December 26, 2016 in our hospital and echocardiographic image by which the LAVI could be measured has not been recorded. Thus LAVI could not be analyzed in this study. Twenty-four patients (18\%) underwent re-ablation for AF recurrence, which may introduce strong patient selection bias. Another major limitation is that this was a retrospective study; prospective confirmation will add further value.

\section{Conclusions}

This study demonstrated that a higher rate of LA size reduction at 6 months after ablation of persistent AF was associated with a higher maintenance rate of sinus rhythm in the late phase. This is a new predictor for maintenance of sinus rhythm after ablation of persistent AF.

\section{Compliance with ethical standards}

Conflict of interest Masaaki Ito received honoraria equal to or more than 500,000 yen from Daiichi Sankyo Company Limited, Bayer Holding Ltd., and Mitsubishi Tanabe Pharma Corporation in 2016, and from Daiichi Sankyo Company Limited, Bayer Holding Ltd., and Takeda Pharmaceutical Company Limited in 2017. The Department of Cardiology and Nephrology, Mie University Graduate School of Medicine was supported in part by unrestricted research grants of equal to or more than 1,000,000 yen from MSD K.K., Astellas Pharma Inc., Takeda Pharmaceutical Company Limited, Otsuka Pharma Inc., Daiichi Sankyo Company Limited, and Shionogi \& Co., Ltd. in 2016, from Bristol-Myers Squibb K.K., MSD K.K., Shionogi \& Co., Ltd., Otsuka Pharma Inc., Takeda Pharmaceutical Company Limited and Daiichi Sankyo Company Limited in 2017, and from Otsuka Pharma Inc. and 
Daiichi Sankyo Company Limited in 2018. Grants of 1,000,000 yen or more annually for research work (collaborative study, consignment study, or clinical trial), which the author is substantially authorized to use, were received from Daiichi Sankyo Company Limited in 2017 and 2018. The other authors declare that they have no conflicts of interest.

Open Access This article is distributed under the terms of the Creative Commons Attribution 4.0 International License (http://creativeco mmons.org/licenses/by/4.0/), which permits unrestricted use, distribution, and reproduction in any medium, provided you give appropriate credit to the original author(s) and the source, provide a link to the Creative Commons license, and indicate if changes were made.

\section{References}

1. Pappone C, Augello G, Sala S, Gugliotta F, Vicedomini G, Gulletta S, Paglino G, Mazzone P, Sora N, Greiss I, Santagostino A, LiVolsi L, Pappone N, Radinovic A, Manguso F, Santinelli $\mathrm{V}$ (2006) A randomized trial of circumferential pulmonary vein ablation versus antiarrhythmic drug therapy in paroxysmal atrial fibrillation: the APAF Study. J Am Coll Cardiol 48:2340-2347

2. Schmitt C, Estner H, Hecher B, Luik A, Kolb C, Karch M, Ndrepepa G, Zrenner B, Hessling G, Deisenhofer I (2007) Radiofrequency ablation of complex fractionated atrial electrograms (CFAE): preferential sites of acute termination and regularization in paroxysmal and persistent atrial fibrillation. J Cardiovasc Electrophysiol 18:1039-1046

3. Verma A, Jiang CY, Betts TR, Chen J, Deisenhofer I, Mantovan R, Macle L, Morillo CA, Haverkamp W, Weerasooriya R, Albenque JP, Nardi S, Menardi E, Novak P, Sanders P, Investigators STARAFII (2015) Approaches to catheter ablation for persistent atrial fibrillation. N Engl J Med 372:1812-1822

4. Reant P, Lafitte S, Jais P, Serri K, Weerasooriya R, Hocini M, Pillois X, Clementy J, Haissaguerre M, Roudaut R (2005) Reverse remodeling of the left cardiac chambers after catheter ablation after 1 year in a series of patients with isolated atrial fibrillation. Circulation 112:2896-2903

5. Senga M, Fujii E, Sugiura S, Yamazato S, Sugiura E, Nakamura M, Miyahara M, Ito M (2010) Efficacy of linear block at the left atrial roof in atrial fibrillation. J Cardiol 55:322-327

6. Sugiura S, Fujii E, Senga M, Sugiura E, Nakamura M, Ito M (2012) Clinical features of patients with left atrial thrombus undergoing anticoagulant therapy. J Interv Card Electrophysiol 34:59-63

7. Li JH, Haim M, Movassaghi B, Mendel JB, Chaudhry GM, Haffajee CI, Orlov MV (2009) Segmentation and registration of three-dimensional rotational angiogram on live fluoroscopy to guide atrial fibrillation ablation: a new online imaging tool. Heart Rhythm 6:231-237

8. Nölker G, Gutleben KJ, Asbach S, Vogt J, Heintze J, Brachmann J, Horstkotte D, Sinha AM (2011) Intracardiac echocardiography for registration of rotational angiography-based left atrial reconstructions: a novel approach integrating two intraprocedural three-dimensional imaging techniques in atrial fibrillation ablation. Europace 13:492-498

9. Fujita S, Fujii E, Kagawa Y, Inoue K, Yamada T, Ito M (2018) The seamless integration of three-dimensional rotational angiography images into electroanatomical mapping systems to guide catheter ablation of atrial fibrillation. Heart Vessels 33:1373-1380
10. Ouyang F, Bansch D, Ernst S, Schaumann A, Hachiya H, Chen M, Chun J, Falk P, Khanedani A, Antz M, Kuck KH (2004) Complete isolation of left atrium surrounding the pulmonary veins: new insights from the double-Lasso technique in paroxysmal atrial fibrillation. Circulation 110:2090-2096

11. Nademanee K, McKenzie J, Kosar E, Schwab M, Sunsaneewitayakul B, Vasavakul T, Khunnawat C, Ngarmukos T (2004) A new approach for catheter ablation of atrial fibrillation: mapping of the electrophysiologic substrate. J Am Coll Cardiol 43:2044-2053

12. Kagawa Y, Fujii E, Fujita S, Yamada N, Ito M (2017) Three cases of vasospastic angina following catheter ablation of atrial fibrillation. J Arrhythm. 33:511-513

13. Tops LF, Bax JJ, Zeppenfeld K, Jongbloed MR, van der Wall EE, Schalij MJ (2006) Effect of radiofrequency catheter ablation for atrial fibrillation on left atrial cavity size. Am J Cardiol 97:1220-1222

14. Beukema WP, Elvan A, Sie HT, Misier AR, Wellens HJ (2005) Successful radiofrequency ablation in patients with previous atrial fibrillation results in a significant decrease in left atrial size. Circulation 112:2089-2095

15. Berruezo A, Tamborero D, Mont L, Benito B, Tolosana JM, Sitges M, Vidal B, Arriagada G, Méndez F, Matiello M, Molina I, Brugada J (2007) Pre-procedural predictors of atrial fibrillation recurrence after circumferential pulmonary vein ablation. Eur Heart J 28:836-841

16. Oral H, Knight BP, Ozaydin M, Tada H, Chugh A, Hassan S, Scharf C, Lai SW, Greenstein R, Pelosi F Jr, Strickberger SA, Morady F (2002) Clinical significance of early recurrences of atrial fibrillation after pulmonary vein isolation. J Am Coll Cardiol 40:100-104

17. Lemola K, Sneider M, Desjardins B, Case I, Chugh A, Good E, Han J, Tamirisa K, Tsemo A, Reich S, Tschopp D, Igic P, Elmouchi D, Bogun F, Pelosi F Jr, Kazerooni E, Morady F, Oral $\mathrm{H}$ (2004) Effects of left atrial ablation of atrial fibrillation on size of the left atrium and pulmonary veins. Heart Rhythm 1:576-581

18. Wu JH, Li HK, Couri DM, Araoz PA, Lee YH, Ma CS, Packer DL, Cha YM (2016) Reversal of pulmonary vein remodeling after catheter ablation of atrial fibrillation. J Geriatr Cardiol 13:163-168

19. Fujimoto Y, Yodogawa K, Takahashi K, Tsuboi I, Hayashi H, Uetake S, Iwasaki YK, Hayashi M, Miyauchi Y, Shimizu W (2017) Noninvasive evaluation of reverse atrial remodeling after catheter ablation of atrial fibrillation by $\mathrm{P}$ wave dispersion. Heart Vessels 32:1375-1381

20. Parikh SS, Jons C, McNitt S, Daubert JP, Schwarz KQ, Hall B (2010) Predictive capability of left atrial size measured by CT, TEE, and TTE for recurrence of atrial fibrillation following radiofrequency catheter ablation. Pacing Clin Electrophysiol 33:532-540

21. Jahnke C, Fischer J, Gerds-Li JH, Gebker R, Manka R, Fleck E, Paetsch I, Kriatselis C (2011) Serial monitoring of reverse leftatrial remodeling after pulmonary vein isolation in patients with atrial fibrillation: a magnetic resonance imaging study. Int J Cardiol 153:42-46

Publisher's Note Springer Nature remains neutral with regard to jurisdictional claims in published maps and institutional affiliations. 